Between Ancient and Modern:

\title{
Entre antigos e modernos: a escrita da história em Chateaubriand. Ensaio sobre historiografia e relatos de viagem
}

the Writing of History in

Chateaubriand. Essay on

Historiography and Travel Reports

\section{Temístocles Cezar}

Professor no Departamento de História da Universidade Federal do Rio Grande do Sul (IFCH I UFRGS - Porto Alegre / Brasil) e bolsista de produtividade em pesquisa do Conselho Nacional de Desenvolvimento Científico e Tecnológico (CNPq) e-mail: t.cezar@ufrgs.br

\section{Resumo}

0 artigo tem por objetivo comentar o artigo de Wilma Peres Costa, Entre tempos e mundos: Chateaubriand e a outra América, a partir de três questões relacionadas à minha formação: I. 0 relato de viagem como instrumento heurístico para a escrita da história; II. A (des)ordem do tempo em Chateaubriand; III. À guisa de conclusão, retomo a hipótese do autor como um vencido que não morre.

\begin{abstract}
This article aims to discuss Wilma Peres Costa's Entre tempos e mundos: Chateaubriand e a outra América from three subjects related to my academic formation: 1. travel report as a heuristic instrument to history writing; 2 . the (dis) order of time in Chateaubriand's work; 3 . in order to build the conclusion, I recapture the assumption of the author as a loser who never dies.
\end{abstract}

\section{Palavras-chave}

historiografia, relatos de viajantes, memórias históricas, literatura

\section{Keywords}

historiography, travelers' accounts, historical memoirs, literature 
CHATEAUBRIAND, René. Études historiques (1831).

CEuvres complètes de Chateaubriand. Paris: Garnier, T.IX, 1861. p.6-7.

LÉVI-STRAUSS, Claude. Tristes tropiques. Paris: Plon, 1955. p.13.

CHATEAUBRIAND, René. Préface générale (1826). CEuvres complètes de Chateaubriand. Paris: Garnier, T.I, 1861. p.235.

CHATEAUBRIAND, René. Mémoires d'outre-tombe (1848). Paris: Gallimard, Bibliothèque de la Pléiade, II, 1952. p.933-934. Ou ainda: "Quatre fois j'ai traversé les mers. (...) Des auteurs français de ma date, je suis quasi le seul qui ressemble à ses ouvrages: voyageur, soldat, publiciste, ministre, c'est dans les bois que j'ai chanté les bois, sur les vaisseaux que j'ai peint l'Océan, dans les camps que j'ai parlé des armes, dans l'exil que j'appris l'exil, dans les cours, dans les affaires, dans les assemblées que j'ai étudié les princes, la politique et les lois". Op. Cit. p.935.

Gostaria de expressar meus agradecimentos aos organizadores e participantes do Fórum, em especial, aos professores Wilma Peres Costa e Marco Morel pelo convite para integrar a mesa de discussão.

NICOLAZZI, F. e ARAÚJO, V. A história da historiografia e a atualidade do historicismo: perspectivas sobre a formação de um campo. In: ARAÚJO, Valdei Lopes de. (org.) A dinâmica do historicismo: revisitando a historiografia moderna. Belo Horizonte: Argvmentvm, 2008. p.10-11.
Je hais les voyages et les explorateurs. (Claude Lévi-Strauss, Tristes Tropiques) $^{2}$

\section{Entre tempos e mundos}

Não, Chateaubriand não odiava as viagens e os exploradores! Atravessou várias vezes os mares, viveu entre os selvagens e em palácios reais, nos campos e nas cidades. Viajou pela Grécia, foi peregrino em Jerusalém, sentou-se sobre todos os tipos de ruínas. Viu passar o reinado de Luis XVI e o império de Bonaparte, dividiu o exilio com os Bourbons, dos quais anunciou o retorno. Dois pesos, que the pareciam arraigados à sua sorte, fizeram-no subir ou descer em uma proporção igual: assim como o prendiam, libertavam-no. Acostumado a essas intempéries, quando chegava a um porto, via-se sempre como um navegador que logo reembarcará, não deixando em terra nenhum estabelecimento sólido. ${ }^{3}$ Ele se ocupou da guerra e da paz, assinou tratados e protocolos diplomáticos; assistiu a congressos e conclaves e também a reedificações e demolições de tronos. Por ter feito a história, por ter muito viajado, julgava-se capaz de escrevê-la. Uma vida solitária e silenciosa que seguia em meio a esse tumulto e barulho acompanhada pelas filhas de sua imaginação: Atala, Amélie, Blanca, Velléda, sem falar daquilo que poderia chamar de suas realidades cotidianas, não fossem elas seduções quiméricas. No final da vida, habitava-Ihe o medo de que fora uma alma maldita. Viajante, escritor, homem de estado, viveu entre dois séculos, como na confluência de dois rios, em cujas águas turvas mergulhou, distanciando-se, contra seu desejo, da velha margem onde nascera, nadando, com esperança, em direção desconhecida. ${ }^{4}$

Entre tempos: o passado, o presente, mas também o descontínuo e a memória; e mundos: o velho e o novo, e, em cada um deles, o antigo e o moderno que se imiscuem e se entrecruzam. Entre tempos e mundos: Chateaubriand e a outra América, de Wilma Peres Costa, nos convida a aventurarmo-nos no cosmos de um personagem de si mesmo, um romântico, marcado pela audácia, pelas contradições e por uma profunda melancolia. ${ }^{5}$

\section{Nota teórico-metodológica}

0 artigo de Wilma Peres Costa situa-se em uma conjuntura de renovação dos estudos em teoria da história e história da historiografia, área cujo número de publicações tem, nos últimos anos, aumentado de forma significativa. Contudo, os trabalhos realizados no Brasil ainda carecem de uma agenda autônoma de investigação no que diz respeito a conceitos, noções e problemas mais específicos. Como ressaltam dois importantes pesquisadores da nova geração, Fernando Nicolazzi e Valdei Lopes de Araújo, a busca da autonomia neste campo "não significa uma produção surda ao diálogo com a história social, cultural ou política", mas se apóia na singularidade dos seus objetos e, portanto, em um questionário próprio. ${ }^{6}$ Nesse sentido, em uma avaliação acerca da historiografia como campo e objeto de pesquisa, Manoel Luiz Salgado Guimarães já assinalara que somente sob o crivo da reflexão histórica, "os textos de história 
GUIMARÃES, Manoel L. S. A cultura histórica oitocentista: a constituição de uma memória disciplinar. PESAVENTO, S. J. História Cultural: experiências de pesquisa. Porto Alegre: UFRGS, 2003. p.21. 8

0 que nada Ihes retira da sua validade e importância cientifica. Tratam-se somente de abordagens diferentes.

9

HARTOG, François. L'histoire tentée par

l'épistémologie? Évidence de l'histoire. Ce que voient les historiens. Paris: Ed. EHESS, 2005. p.230-235.

10

HARTOG, François. Le miroir d'Hérodote. Essai sur la représentation de l'autre. Paris: Gallimard, 1991; Idem. Le XIXe siècle et I'histoire. Le cas Fustel de Coulanges. Paris: PUF, 1988; Idem. Temps et histoire. 'Comment écrire l'histoire de France ?'. Annales, 1995, 6, p.1219-1236; Idem. Mémoire d'Ulysse: récits sur la frontière en Grèce ancienne. Paris: Gallimard, 1996; Idem. L'histoire d'Homère à Augustin: préfaces des historiens et textes sur I'histoire. Paris: Seuil, 1999; Idem. Os Antigos, o passado, o presente. Brasilia, UnB, 2003; Idem. Régimes d'historicité, présentisme et expérience du temps. Paris: Seuil, 2003; Idem. Temps du monde, histoire, écriture de l'histoire. L'Inactuel, 12, 2004, p.93-102; Idem. Évidence de I'histoire. Ce que voient les historiens. Paris: Ed. EHESS, 2005; Idem. Anciens, modernes, sauvages. Paris: Galaade, 2005.

11

CHATEAUBRIAND, René. Congrès de Vérone. CEuvres complètes de Chateaubriand. Paris: Garnier, T.XII, 1861. p.5-112.

12

0 debate que se sucedeu à apresentação dos textos no Fórum além de me corrigir equivocos de interpretação, suscitou a mim e audiência uma série de questões cuja análise depende de pesquisas mais especificas. No entanto, ressalto algumas a fim de tentar recriar um pouco a cor local da discussão: o professor István Jancsó propôs o debate acerca da relação entre história da historiografia e história política; João Paulo Pimenta salientou a particularidade do regime de historicidade brasileiro no qual haveria uma pluralidade de concepções de história (historia magistra vitae, o progresso como medida do tempo etc.), além de destacar a importância da circulação de idéias a partir dos relatos de viagem; Andréa Slemian colocou a questão da reversibilidade das revoluções e da crise das monarquias ressaltando a importância do pensamento de Benjamin Constant nesse contexto; André de Arruda Machado e Fernanda Sposito, por sua vez, realçaram o papel de Chateaubriand no Império Brasileiro e sua influência sobre o movimento romântico.

13

HOENEN, R. le. Qu'est-ce qu'un récit de voyage? Littéralis, (Les modèles du récit de voyage). Cahiers du Département de Français de Paris X - Nanterre: 1990. p.11-27. Para uma tentativa de compreender os relatos de viagem como um gênero literário ver DOIRON, N. De l'épreuve de l'espace au lieu du texte: le récit de voyage comme genre. Voyages, récits et imaginaire. Montreal: B. Beugnat, 1984 p.15-31. deixam de ser meros pretextos para se constituírem em núcleos centrais de investigação".7 Tradicionalmente orientados pela exterioridade dos pressupostos de investigação, os estudos historiográficos privilegiaram uma démarche mais descritiva de autores e obras, na qual os aspectos ideológicos ou econômicos dos contextos de produção sempre foram evocados como princípio explicativo preponderante da interpretação histórica. ${ }^{8}$ Mais recentemente, algumas pesquisas na área passaram a propor problemas historiográficos, ancorando-se em uma preocupação epistemológica de historicizar os pressupostos teóricos e as práticas da escrita da história. De um modo geral, percebe-se a emergência de uma perspectiva de trabalho que, segundo François Hartog, pretenda estar "mais vigilante às sirenes dos reducionismos". 9

Wilma Peres Costa, atenta a essas recomendações, parte justamente das considerações sobre Chateaubriand desenvolvidas por Hartog. Especialista em historiografia antiga e moderna, o historiador francês submete a obra de Chateaubriand a um conjunto de problemas teóricos que orientam suas pesquisas nas últimas três décadas, a saber: as diferentes temporalidades que caracterizam o discurso histórico (os regimes de historicidade), os relatos de viagem como fundamento historiográfico e as distintas modalidades que a escrita da história pode assumir.10 Além de incorporar essas reflexões com prudência metodológica, a autora avalia aspectos específicos, não considerados por Hartog em a Voyage en Amérique, bem como acrescenta o relato de Chateaubriand sobre o Congresso de Verona de 1822, do qual participou como ministro plenipotenciário do governo da França. ${ }^{11}$

Meu comentário ao artigo de Wilma Peres Costa concentra-se em três questões mais relacionadas à minha formação: I. 0 relato de viagem como instrumento heurístico para a escrita da história; II. A (des)ordem do tempo em Chateaubriand; III. À guisa de conclusão, retomo a hipótese do autor como um vencido que não morre. ${ }^{12}$

\section{Relato de viagem e escrita da história}

0 relato de viagem é um gênero literário sem lei. Apesar de sua tradição ser bem estabelecida e sua leitura atravessar o tempo, este tipo de escrita continua avesso a debates teóricos..$^{13}$ Contudo, mesmo sendo uma narração fugidia que resiste a toda descrição minuciosa que não seja uma simples taxonomia de seus conteúdos, a versatilidade do texto que narra uma viagem se manifesta através de uma certa liberdade formal e de uma plasticidade que o tornam adaptável a numerosas sociedades.

Por outro lado, o relato de viagem pode se fixar sobre determinadas formações discursivas e ser regrado por códigos especificos. Assim, por exemplo, o encontramos integrado às matérias de um diário (o Journal de voyage de Montaigne), de uma autobiografia ou de um ensaio etnográfico (o Tristes tropiques de Claude Lévi-Strauss), de obras epistolares (as Lettres d'un voyageur de George Sand), ou ainda retranscrito em forma diversa daquela de sua primeira ocorrência (como, por exemplo, Voyage au Canada, relato retrospectivo em que Jacques Cartier retoma as notas de vários diários de bordo). Da mesma maneira que pode se adaptar às exigências desse conjunto de possibilidades literárias, o relato de viagem se constitui em um campo disponivel aos múltiplos discursos que o percorrem e que o articulam, tais como o do antigo cosmógrafo, do geógrafo, do naturalista, do etnógrafo, do 
ASSIS, Machado de. Uma excursão milagrosa. Obra completa. Rio de Janeiro: Nova Aguilar, 2006, v.2. p.759. 15

Ver, neste sentido, o questionamento inicial de P. Aniel Jannini que, ao analisar o relato de Champlain se questiona, "La ricezione dei 'voyage' di Champlain nella storiografia letteraria". Quaderni del seicento francese. Adriatica-Bari/ Nizet-Paris: 1984. p.27.

16

HARTOG, François. Le miroir d'Hérodote. Essai sur la représentation de l'autre. Paris: Gallimard, 1991. p.272. 17

Citado por LENCLUD, Gérard. Quand voir, c'est reconnaître: les récits de voyage et le regard anthropologique. Enquête, 1, 1995, p.129.

\section{8}

É também de trocas intelectuais, como analisa Mary Louise Pratt: "To the degree that

'Romanticism' shapes the new discourses on America, Egypt, southern Africa, Polynesia, or Italy, they shape it. Romantics are certainly known for stationing themselves round Europe's peripheries - the Hellespont, the Alps, the Pyrenees, Italy, Russia, Egypt. Romanticism consists, among other things, of shifts in relations between Europe and other parts of the world - notably the Americas, which are, precisely, liberating themselves from Europe. If one unhoks Humboldt from Schiller and locates him in another 'Romantic' line - George Forster and Bernardin de St. Pierre (two of Humboldt's personal idols), Volney, Chateaubriand, Stedman, Buffon, Le Vaillant, Captain Cook, and the Diderot of the 'Supplement to the Voyage of Bougainville' - one might be tempted to argue that Romanticism originated in the contact zones of America, North Africa, and the Sound Seas", PRATT, M. L. Imperial eyes. Travel writing and transculturation. London and New York: Routledge, 1994. p.137-138.

19

Para uma visão geral do período ver: GOSSMAN, Lionel. Between history and literature. Cambridge: Harvard University Press, 1990; BANN, Stephen. The clothing of Clio. A study of the representation of history in nineteenth-century Britain and France. Cambridge: Cambridge University Press, 1984; Idem. Romanticism and the rise of history. New York: Twaim Publishers, 1995; GAUCHET, Marcel. L'unification de la science historique. Philosophie des sciences historiques. Le moment romantique. Paris: Seuil, 2002. Expecificamente para um Ranke "romântico", ver GRAFTON, Anthony. Les origines tragiques de l'érudition. Une histoire de la note en bas de Page. Paris: Seuil, 1998. Procurei analisar Varnhagen nessa perspectiva em CEZAR, Temistocles. Varnhagen em movimento: breve antologia de uma existência. Topoi, v.8, n.15, 2007. p.159-207.

20

GOETHE, J. W. Voyage en Italie. Paris/Genève:

Slatkine Reprints, 1990. p.44; p.121-122. Sobre a importância de Tácito na obra de Chateaubriand ver HARTOG, François. L'histoire d'Homère à Augustin: préfaces des historiens et textes sur I'histoire. Paris: Seuil, 1999. p.223.

21

CHATEAUBRIAND, René. Itinéraire de Paris à Jérusalem (1811). OEuvres complètes de Chateaubriand. Paris: Garnier, T.V, 1861. p.4. administrador e do economista, do militar, do missionário, do arqueólogo, do marchand e do amante de obras de arte, e, enfim, do escritor e do historiador. Cada um deles é dotado de seu próprio léxico, o que não os impede de se cruzarem reciprocamente. Trata-se de um texto cuja condição fragmentária o torna passível de ser apreendido segundo o desejo do receptor; assim, se "viajar é multiplicar-se", segundo Machado de Assis ${ }^{14}$ (que curiosamente não gostava de viajar!), então o relato de viagem é uma escrita que desconhece fronteiras. ${ }^{15}$

No entanto, se de um lado existe uma pluralidade de recepções, de outro, um ponto parece ser comum a todas: o conteúdo dos relatos seria uma manifestação da verdade daquilo que os viajantes viram; parece haver uma intenção de verdade no texto, efeito da autópsia, isto é, do "olho como marca de enunciação, como intervenção do narrador no relato, para provar".16 É muito provável que seja por esta razão que a historiografia, sobretudo a partir do século XIX, momento de sua primeira aproximação com a ciência, passa a servir-se desses relatos como documento histórico. Uma fonte que viu o que descreve e experimentou o que viu. Pelo menos é o que os viajantes afirmam... Não seria, todavia, um excesso de zelo ter em mente o que dizia o velho capitão Burton: "ver não é saber, mas crer".17

Para os românticos da virada do século XVIII e início do século XIX, viajar é uma experiência intelectual imprescindivel. 0 deslocamento no espaço os auxilia a pensar sobre um conjunto de materiais novos $e_{\text {, }}$ principalmente, diferentes. ${ }^{18}$ Os clássicos românticos europeus, como Chateaubriand, Goethe, Wordsworth, Byron, Shelley, Keats, Espronceda, Garret, Herculano, Michelet e mesmo Ranke, e, no caso do Brasil, de Varnhagen, foram marcados pelas viagens. ${ }^{19}$

0 tipo de conhecimento que emana dessas experiências não incide apenas nos gêneros ficcionais da escrita, mas afeta também os saberes que buscam a descrição exata ou verdadeira, mesmo nos ficcionistas. Assim, por exemplo, em seu diário de viagem à Itália, Goethe, passando por Verona, registra: "eu não fiz esta maravilhosa viagem para me entreter, mas para aprender a me conhecer no contato das coisas". Em Terni, provável pátria de Tácito, modelo de historiador para Chateaubriand, Goethe afirma: "Quando não nos deixamos guiar pela imaginação, mas tomamos a região na sua realidade tal qual se apresenta, é ela sempre o teatro essencial que determina as grandes ações; por esta razão sempre recorri, até aqui, às observações e ao estudo da paisagem para reprimir a imaginação e o sentimento, e assim conservar uma visão livre e clara dos lugares. Então a história vem ao nosso encontro de uma maneira viva, sem que compreendamos como isto nos acontece; e tenho o maior desejo de ler Tácito em Roma".20

Chateaubriand, em seu Itinéraire de Paris à Jerusalem, de 1811, não somente ratifica as relações entre viagem e história, como estabelece um princípio teórico e metodológico que aproxima a figura do historiador à do viajante. Para ele "um viajante é uma espécie de historiador", e como para esse, "seu dever é o de relatar fielmente aquilo que viu e escutou dizer, nada deve inventar, nem omitir", e, finalmente, "sejam quais forem suas opiniões particulares, elas não devem jamais cegá-lo a ponto de calar ou deturpar a verdade". ${ }^{21}$ À pretensão do literato interpõe-se uma condição vital: o tempo transcorrido. 0 relato de viagem é um produto 
CHATEAUBRIAND, René. Itinéraire de Paris à Jérusalem (1811). OEuvres complètes de Chateaubriand. Paris: Garnier, T.V, 1861. p.3.

23

CHATEAUBRIAND, René. Mémoires d'outre-tombe (1848). Paris: Gallimard, Bibliothèque de la Pléiade, I, 1952. p.601-628. Sobre os capitães, ver SAHLINS, Marshall. Ilhas de história. Rio de Janeiro: Jorge Zahar, 1990.

24

CHATEAUBRIAND, René. Voyage en Amérique (1827). OEuvres complètes de Chateaubriand. Paris: Garnier, T.VI, 1861. p.5.

25

Segundo Daniel Roche, "il peut sembler intéressant de tenter de comprendre les usages du voyage à partir des moyens, qu'ils soient supports de rêve ou guide de l'action, occasion de fuite dans l'imaginaire exotique ou proche, ou encore moyen de connaissance. C'est un point de vue indispensable et préalable à toute lecture des récits de voyage car les pratiques de réception y induisent beacoup d'effects". Roche, D. "Le voyageur en chambre: réflexion sur la lecture des récits de voyage". In: BURGUIĖRE, A.; GOY, J.; TITS-DIEUAIDE, M-J. (Dir). L'histoire grande ouverte: hommage à Emmanuel Le Roy Ladurie. Paris: Fayard, 1997. p.552.

26

CHATEAUBRIAND, René. Voyage en Amérique (1827). Op.Cit. p.6.

27

MANDELSTAM, Ossip. Selected Poems. New York: Pinguin Books, 1989. p.28.

28

HARTOG, François. Le miroir d'Hérodote. Essai sur la représentation de l'autre. Paris: Gallimard, 1991. p.359. 0 autor explica que em seu trabalho "o texto de Heródoto é tratado como uma narrativa de viagem, isto é, como uma narrativa que tem a preocupação de traduzir o outro em termos do saber compartilhado pelos gregos e que, para fazer crer no outro que constrói, elabora toda uma retórica da alteridade", idem, p.19. Segundo Arnaldo Momigliano Heródoto foi, entre os autores da antiguidade, aquele que mais viajou, o que Ihe confere também o título de pai da etnografia. MOMIGLIANO, A. Les fondations du savoir historique. Paris: Les Belles Lettres, 1992. p.58-59.

29

WHITE, Hayden. Meta-história. A imaginação histórica do século XIX. São Paulo: Edusp, 1992. p.12. 30

LÉVI-STRAUSS, Claude. Tristes tropiques. Paris: Plon, 1955. p.103. Para as informações sobre Nearco e Colombo, ver HARTOG, François. Le miroir d'Hérodote. Op.Cit. p.362. Sobre Voyage du jeune Anacharsis ver HARTOG, François. Régimes d'historicité, présentisme et expérience du temps. Paris: Seuil, 2003. p.81. Ver também: GINZBURG, Carlo. Anacharsis interroga gli indigeni. Una nuova lettura di um vecchio best-seller. In: In: BURGUIĖRE, A.; GOY, J.; TITS-DIEUAIDE, M-J. (Dir). Op.Cit. p.337-346.

31

CHATEAUBRIAND, René. Voyage en Amérique (1827). Op.Cit. p.3-4, p.10.

32

HARTOG, François. Le miroir d'Hérodote. Op.Cit. p.303. de notas escritas in locus, mas também, e principalmente, de um exercício de memória: "eu rogo ao leitor que olhe este Itinéraire menos como uma viagem do que como memórias de um ano de minha vida".22 Realizada entre 1806 e 1807, Chateaubriand se fez acompanhar de um valet, Julien, que também redigiu seu Itinéraire. Nos breves capítulos das Mémoires d'outre tombe dedicados a essa viagem, ele intercala em seu próprio relato memorialístico aquele de Julien, com o objetivo de criar um controle sobre a narração: "eu seria Cook, ele Clerke".23 0 contraste gera uma segurança textual: ator e testemunha garantiriam a veracidade das informações.

"As viagens são uma das fontes da história". 24 Dessa forma, Chateaubriand começa o relato de sua Voyage en Amérique, ocorrida em 1791, mas que só vem a lume em 1827. É uma prática comum no século XIX, especialmente da geração romântica, converter textos de viagem em documentos históricos. 0 procedimento de conversão varia desde uma aplicação rígida do método crítico (verificação efetiva da veracidade do texto e do autor) à aquiescência irrefletida. 0 fato de os relatos funcionarem ora como suporte de sonhos e ilusões, ora como guias de ação, não Ihes subtrai, entretanto, o valor cognitivo, ou o efeito de real que eles provocam no leitor. ${ }^{25}$ Desde Ulisses e Heródoto, o discurso do viajante relaciona-se ao conhecimento: "Heródoto, o pai da história como Homero é o pai da poesia, era como Homero um viajante", pensava Chateabriand26; "Ulisses retornou pleno de espaço e de saber", sintetizava o poeta Ossip Mandelstam27; "os viajantes e outros agrimensores não tenderão a ver o mundo através dos óculos de Heródoto? As Histórias não se tornarão esse espelho em que eles verão o mundo, crendo descrevê-lo?", pergunta Hartog. ${ }^{28}$

De certo modo sim, pois é possivel considerar a estrutura do texto de viagem como um componente do nível profundo da consciência, a partir do qual o historiador do século XIX escolhe as estratégias conceituais com as quais explica ou representa e converte os dados que dispõe para compor a escrita da história. ${ }^{29}$ Logo, não é surpreendente que Nearco, navegador cretense do séc. IV a.C que acompanhou Alexandre o Grande à Índia, tenha levado consigo as Histórias de Heródoto; que Cristovão Colombo guardasse em seu bolso, na viagem ao Novo Mundo, Marco Polo; que Lévi-Strauss mantivesse junto de si, no percurso dos Tristes trópicos, seu breviário, Jean de Léry; e que Chateaubriand tenha se guiado na sua viagem intelectual aos antigos por um dos best-sellers do momento, a Voyage du jeune Anacharsis, publicada pelo abade JeanJacques Barthélemy em 1788. ${ }^{30}$ Ou ainda, em Voyage en Amérique, no prefácio que nada mais é do que uma "espécie de história das viagens", ele explica que buscará "os anéis da cadeia que liga os viajantes antigos aos viajantes modernos". ${ }^{31}$ Em suma, de modo geral, a narrativa do viajante jamais é um aparecimento original, ela é sempre tomada em uma outra narração, ou seja, o percurso de um relato de viagem é também o percurso de outros relatos. ${ }^{32}$

\section{A (des)ordem do tempo em Chateabriand}

A companhia de Barthélemy se fez necessária na redação do Essai historique sur les révolutions anciennes et modernes, cuja edição original aparece em 1797, portanto em data anterior à publicação de seus relatos 
CHATEAUBRIAND, René. "Essai historique, politique et moral sur les révolutions anciennes et modernes, considérées dans leurs rapports avec la révolution françoise (1797)". OEuvres complètes de Chateaubriand. Paris: Garnier, T.I, 1861.

34

HARTOG, François. Régimes d'historicité, présentisme et expérience du temps. Paris: Seuil, 2003. p.81. "Au reste, l'auteur, qui a visité différentes parties du globe, et qui, par son titre d'Essai, a pu s'écarter çà et là sur sa route, s'est quelquefois permis d'insérer des morceaux de ses Voyages". CHATEAUBRIAND, René. "Essai historique, politique et moral sur les révolutions anciennes et modernes...." Op.Cit. p.264. 35

CHATEAUBRIAND, René. "Essai historique, politique et moral sur les révolutions anciennes et modernes...". Op.Cit. p.266.

36

Ibidem. p.249.

37

KOSELLECK, Reinhart. "Le concept d'histoire", L'expérience de I'histoire. Paris: Hautes Études/ Gallimard/Le Seuil, 1997. p.80.

38

AVLAMI, Chryssanti. Visões liberais da política da literatura e da religião grega: o caso francês (17951830). Humanas, v.23, n.1/2, 2000. p.45-85 (principalmente p.51).

39

CHATEAUBRIAND, René. "Essai historique, politique et moral sur les révolutions anciennes et modernes...". Op.Cit., p.276.

40

Ibidem. p.465.

41

MARX, Karl. 018 Brumário de Luis Bonaparte

(1852). Obras escolhidas. São Paulo: Alfa-Ômega, v. I, s/d. p.203.

42

KOSELLECK, Reinhart. Historia magistra vitae, Futuro passado. Contribuição à semântica dos tempos históricos. Rio de Janeiro: Contraponto/Ed. da PUC-RJ, 2006. p.59.

\section{3}

HARTOG, François. Anciens, modernes, sauvages. Paris: Galaade, 2005. p.197-219. Para as definições do paralelo e da comparação como figuras de linguagem no século XIX, ver FONTANIER, Pierre. Les figures du discours (1830). Paris: Flammarion, 1977. p.377-379.

44

HARTOG, François. Régimes d'historicité, présentisme et expérience du temps. Paris: Seuil, 2003. p.99.

45

LIMA, Luiz Costa. História, ficção, literatura. São Paulo: Companhia das Letras, 2006. p.125. de viagem. ${ }^{33} 0$ Essai historique é "em primeiro lugar, um relato de viagem: viagem para o Novo Mundo sem dúvida, mas também viagem interior". 34 Jovem, doente e desolado, Chateaubriand mergulha na relação entre antigos e modernos, situando-se desde o início em sua própria escrita: "quem sou e o que venho anunciar de novo aos homens?", assim começa o Essai historique. Mais do que um livro, trata-se de um "diário regular de suas excursões mentais, registro de seus sentimentos, de suas idéias" de um mundo que não apenas desmoronava como transcorria rapidamente: "quando deixei a França eu era jovem: quatro anos de desgraça envelheceram-me". 35 Escrito entre 1794 e 1797, o livro busca, inicialmente, estabelecer um paralelo entre as pretéritas e as novas revoluções, procurando, através de um modelo tradicional de história - a história como portadora de exemplos -, verificar a passagem do passado para o futuro. No entanto, o tempo não ajudava: "freqüentemente era necessário apagar à noite o quadro que havia esboçado durante o dia; os eventos corriam mais rápido do que a minha pena". ${ }^{36}$ Algo semelhante declarava, em 1843, o teórico da história Lorenz Stein sobre sua contemporaneidade: "é como se a historiografia mal conseguisse acompanhar a história". 37

Era difícil escrever a história da Revolução Francesa por meio do paralelismo histórico com as revoluções anteriores, pois o paralelo, como instrumento heurístico intrínseco ao regime de historicidade marcado pela noção da historia magistra vitae, cujo fundamento é a imutabilidade da natureza humana, mostrava-se pouco eficiente. ${ }^{38}$ Além disso, o paralelo, como inventário de semelhanças, implicava na produção de modelos passíveis de imitação: "apreendi somente os grandes traços, aqueles que oferecem lições a serem seguidas ou exemplos a serem imitados". 39 Contudo, Chateaubriand também percebia a imitação como uma possibilidade arriscada: "o perigo da imitação é terrivel. Aquilo que é bom para um povo, raramente o é para outro".40 Ou como escreverá Marx mais tarde, corrigindo a lei hegeliana da repetição histórica com uma crítica irônica à imitação: à tragédia sucede a farsa! ${ }^{41} \mathrm{~A}$ história exemplar dissolvia-se diante da aceleração do tempo. ${ }^{42}$

Mesmo convencido, pela experiência, da inadequação do paralelo entre antigos e modernos, Chateaubriand reedita o Essai historique em 1826, sem alterar o texto original, apenas acrescentando-Ihe um prefácio e notas críticas que visavam demarcar a distância entre a maturidade do escritor e a juventude supostamente ameaçada (pelos infortúnios do exilio) do viajante. ${ }^{43}$ Entre tempos e mundos: "o topos da historia magistra torna-se impossivel, mas não é possivel abandoná-lo: não ainda".44 Uma dupla impossibilidade portanto: Chateaubriand encontra-se preso, ou condenado, entre dois regimes de historicidade, o antigo e o moderno. Enquanto Luiz Costa Lima vê neste entrelaçamento de vida e obra um dos efeitos mais surpreendentes de 1789: a escrita da história como descontinuidade; 45 Hartog visualiza uma primeira formulação da brecha entre o passado e o futuro, cujo diagnóstico devemos a Hannah Arendt: "do ponto de vista do homem, que vive sempre no intervalo entre o passado e o futuro, o tempo não é um contínuo, um fluxo de ininterrupta sucessão; é partido ao meio, no ponto onde 'ele' está; e a posição 'dele' não é o presente, na sua acepção usual, mas, antes, uma brecha no tempo, cuja existência é conservada graças à 'sua' luta 
ARENDT, Hannah. Between past and future. New York: The Viking Press, 1961. p.11.

47

HARTOG, François. Régimes d'historicité, présentisme et expérience du temps. Paris: Seuil, 2003. p.100.

48

CHATEAUBRIAND, René. "Essai historique, politique et moral sur les révolutions anciennes et modernes, considérées dans leurs rapports avec la révolution françoise (1797)". OEuvres complètes de Chateaubriand. Paris: Garnier, T.I, 1861. p.622.

49

CHATEAUBRIAND, René. "Essai historique, politique et moral sur les révolutions anciennes et modernes...". Op.Cit. p.627.

50

CHATEAUBRIAND, René. Voyage en Amérique

(1827). OEuvres complètes de Chateaubriand. Paris: Garnier, T.VI, 1861. p.42, p. 194

51

GREENBLATT, Stephen. Marvelous possessions. The wonder of the new World. Oxford: Oxford University Press, 1991. 0 livro de André Thevet, Les Singularités de la France Antarctique de 1557, obra que foi redigida em companhia do helenista Mathurin Héret, é um exemplo notável do uso da comparação dos antigos e selvagens visando à incorporação desses no mundo daqueles. Procurei tratar do assunto em CEZAR, Temistocles. Thevet e Léry: visão, crença e história no Brasil do século XVI. Ensaio sobre historiografia e relatos de viagem. Ciências \& Letras, Porto Alegre, n.37, p. 27-43, jan./jun, 2005.

52

HARTOG, François. Anciens, modernes, sauvages. Paris: Galaade, 2005. p.38.

53

Sobre estes debates ver PAGDEN, Anthony. The fall of natural man. Cambridge: Cambridge University Press, 1982. p.27-108. Ver também do mesmo autor: "Dispossessing the barbarian: the language of Spanish Thomism and the debate over the property rights of the American Indians". PAGDEN, A. (org). The languages os political theory in earlymodern Europe. New York: Cambridge University Press, 1990.

54

LAFITAU, Jean-François. Moeurs des sauvages américains, comparées aux premiers temps (1724). Paris: La Découverte, 1994; ROUSSEAU, JeanJacques. Discurso sobre a origem e os fundamentos da desigualdade entre os homens (1754). São Paulo: Nova Cultural, 1987; CHATEAUBRIAND, René. "Essai historique, politique et moral sur les révolutions anciennes et modernes..." Op.Cit. DESCARTES, René. Discours de la méthode (1637). Paris: Flammarion, 1966. p.36-37; VOLTAIRE. Essai sur les moeurs et l'esprit des nations (1755). Paris: Garnier, 1963, T.I. p.23-25.

55

CHATEAUBRIAND, René. "Essai historique, politique et moral sur les révolutions anciennes et modernes..." Op.Cit. p.622. constante, à 'sua' tomada de posição contra o passado e o futuro". 46 As Mémoires d'outre tombe, escritas e reescritas durante quarenta anos, faria dessa brecha no tempo o princípio de sua arte literária. 47

Chateaubriand termina seu ensaio de modo desconcertante. Sempre sob a assumida influência de Rousseau, faz um apelo ao retorno à vida ou à liberdade dos nativos americanos. Em "A noite entre os selvagens da América", título do último capítulo, o explorador recorda: "vangloriam-se de amar a liberdade, mas quase ninguém faz dela uma justa idéia"; e conclui: "compreendo porque um selvagem não se torna um europeu e porque, muitas vezes, europeus se tornam selvagem; e porque o sublime Discours sur l'inègalité des conditions é tão pouco entendido pela maioria dos filósofos".48 Porém, o paralelo entre antigos e selvagens, caracterizado por semelhanças ou afastamentos, produz a idéia nova de que existe uma analogia entre o deslocamento no espaço e no tempo: "Generosos Selvagens! Vocês que me deram hospitalidade, e que sem dúvida jamais reverei".49 Não voltaria a vê-los posto que não pretendia retornar? Porquanto temia a morte? Ou ainda porque, como declara em Voyage en Amérique, mesmo estando entre aquela multidão de "viajantes obscuros que viram apenas o que todo mundo viu", e apesar de se apresentar como o "último historiador dos povos da terra de Colombo", acreditava que tais povos não tardariam a desaparecer?50

0 recurso aos antigos e modernos, independentemente das celeumas que possam causar, possibilitou a inserção dos nativos do Novo Mundo em uma rede de referências conhecidas dos europeus, que racionalizou o encantamento inicial, essa experiência com o maravilhoso, segundo Stephen Greenblat, provocado pela "descoberta" e que, de uma certa forma, contribui para a "domesticação" dos nativos. ${ }^{51}$ Assim, "ver os selvagens, descrevê-los mobilizando referências antigas, conduz, sem mesmo nos darmos conta, a um distanciamento dos antigos. Apreciaremos, quase fisicamente, a distância que nos separa e se poderá abrir o caminho da diferença moderna dos tempos. Entre os antigos e nós, passará a existir um oceano!". ${ }^{2}$ A entrada em cena dos selvagens não foi, contudo, totalmente desestabilizadora da relação entre os antigos e os modernos. A integração do "selvagem" à disputa passa, em resumo, pela querela, fundamentada na Política de Aristóteles, em torno da questão da escravidão por natureza àquela da natureza infantil dos indios, o que poderia Ihes garantir um lugar na humanidade. ${ }^{53}$ Enquanto Lafitau, Rousseau e Chateaubriand, de maneiras diferentes, refletem sobre essas condições desde as origens (a religião primordial, por exemplo) até as possibilidades de assimilação ou de retorno à vida selvagem, Voltaire, na trilha de Descartes, afasta a possibilidade de o homem moderno não viver em um tipo de sociedade que não fosse regida pela razão, momento em que a selvageria passa, novamente, a opor-se à civilização. ${ }^{54}$ Por conseguinte, outra querela se instala a partir dai: entre antigos, modernos e "selvagens".

\section{Um vencido que não morre}

0 arquivo das distintas experiências temporais de Chateaubriand, intelectual e/ou pessoal, ressaltadas com propriedade por Wilma Peres Costa, tornou-se, conforme sua longa vida transcorria, acessivel apenas pela memória, procedimento já previsto no Essai historique: "trata-se de um sentimento natural aos infelizes procurar lembrar as ilusões de felicidade pela recordação de seus prazeres passados". ${ }^{55} \mathrm{~A}$ escrita da 
Sobre o tema ver: MACHEREY, Pierre. L'Essai sur les Révolutions ou laboratoire d'un style. Europe, 775, 1993, p.29-45.

57

CHATEAUBRIAND, René. Mémoires d'outre-tombe (1848). Paris: Gallimard, Bibliothèque de la Pléiade, II, 1952. p.257.

58

Mutation de l'expérience et changement de méthode. Esquisse historique-anthropologique. KOSELLECK, Reinhart. L'expérience de I'histoire. Paris: Hautes Études/Gallimard/Le Seuil, 1997. p.239-241.

59

WINOCK, Michel. Un royaliste insoumis. Les voix de la liberté. Les écrivains engagés au XIXe siècle. Paris: Seuil, 2001. p.47-62.

60

THIERRY, Augustin. Récits des temps mérovingiens, précédés de Considérations sur I'histoire de France. Paris: Garnier, 1840. p.8-9.

61

CLÉMENT, Jean-Paul. Chateaubriand et la 'fièvre des ruines', Anabases. Traditions et réception de I'Antiquité, Toulouse, 5, 2007, p.179-189

62

GOETHE, Johann. W. von. Fausto (1833). São Paulo, Belo Horizonte: Ed. Itatiaia/São Paulo: Ed. da USP, 1981. p.79.

63

"Trata-se de aquisição para sempre, mais que de uma peça para um concurso", Prefácio à História da guerra do Peloponeso, apud HARTOG, François. L'histoire d'Homère à Augustin: préfaces des historiens et textes sur l'histoire. Paris: Seuil, 1999, 22, (4), p.83. MICHELET, J. Préface (1869). Histoire de France. OEuvres complètes. Paris: Flammarion, 1974. p.11-14.

64

PROUST, Marcel. Sur Chateaubriand. Essais et articles. Paris: 1994. p.348. história retira da memória não apenas um estilo particular, mas também a sua condição de existência. ${ }^{56} 0$ tempo que escoa naturalmente fica retido no arquivo mnemônico do viajante. A viagem no espaço se subtrai e resiste assim ao tempo. Duas conseqüências: o dispositivo narrativo torna-se produto de um certo olhar distanciado, e as lembranças adquirem contornos que o auxiliam a julgar sua própria obra em relação a experiência de um tempo desorientado. Nesse sentido, em 1828, de Roma escrevia: "quando passeio sozinho em meio a estes escombros de séculos, eles não me servem mais apenas como degrau para medir o tempo: eu remonto no passado, vejo aquilo que perdi e o fim deste curto futuro que tenho diante de mim". 57

Na melancolia de Chateaubriand, expressa, portanto, também em sua obra, Hartog identifica o saber de um vencido existencial, seguindo o rastro de Koselleck. Para este historiador, "o fato de ser um vencido constitui uma experiência histórica especifica e original que não se aprende, nem se troca, e que permite a elaboração de um método capaz de conferir a um ganho de experiência uma existência durável". Além disso, "a experiência que tiramos de uma derrota concentra um potencial de conhecimento que sobrevive àquilo que a ocasionou, em particular quando em razão de sua própria história o vencido é coagido a reescrever uma história". Dessa maneira, "pode-se explicar um bom número de inovações no domínio das interpretações históricas na origem das quais encontramos tanto derrotas pessoais como pressões de experiências especificas de gerações inteiras". ${ }^{8}$ Viajante, soldado, homem de letras e de estado, realista insubmisso 59 , vencido, enfim, Chateaubriand não foi um historiador stricto sensu, pelo menos não nos moldes do século XIX, pois a história científica não era capaz de expressar a radicalidade de suas experiências. Ele então inova, cria, inventa um gênero, uma história à Chateaubriand! Por exemplo, a descrição que fizera dos bárbaros franks "encantou" de tal maneira ao historiador Augustin Thierry, em 1840, que o levou a repensar a origem nacional da França: "à medida que se desenrolava a meus olhos o contraste tão dramático do guerreiro selvagem e do soldado civilizado, eu era surpreendido cada vez mais vivamente; a impressão que me causou o canto de guerra dos francos tinha alguma coisa de elétrico".60

Existem homens que aparentemente não morrem, porém todos enveIhecem. Chateaubriand envelheceu, logo ele que detestava a velhice! 61 Velhos ou não, alguns, que talvez nem tenham existido, continuam vivos. Conseguem, não se sabe como, transcender à morte. A "morte nunca é uma aparição bem vista", dizia Mefistófeles a Fausto. ${ }^{62}$ Chateaubriand (como Brás Cubas, mais tarde) parecia conhecer este diabólico provérbio: viveu além-tumba. Não apenas por sua obra significar uma "aquisição para sempre", como desejava Tucídides em relação à sua, mas algo mais próximo a Michelet, cujo livro the teria criado: "Eu fui sua obra. Esse filho fez seu pai".63 Chateaubriand, como pensava Proust, parece, finalmente, que "vive de uma vida na qual não se morre".64 